\title{
Polypharmacy in the geriatric psychiatry department of Saint Alban Hospital
}

\author{
A Hamzaoui*, A Joulié and Y E1 Dachri \\ Pharmacy Department and Medical Information Department, Francois Tosquelles Hospital, France
}

\section{Introduction}

In France, $24.4 \%$ of the population, so almost 1 out of 4 inhabitants, is 65 years old or more. It represents around 11.6 million people and this proportion is still increasing. This can be explained in a way by the post-war baby boomers getting old, and some experts forecast that an important aging process is about to happen during the next twenty years. At nationwide level, this phenomenon is unequally distributed spread and varies from a department to another. For example we find a lot of elder people in Lozère department, located in Occitanie region. According to 2016 Scansanté data [1], 30.6\% of Lozère people were 65 years old or more in 2015 whereas this rate is $27 \%$ in Occitanie and $24 \%$ in France globally. In addition, Lozère suffers from a quite low birth rate according to 2015 INSEE (National Institute of Statistics and Economic Studies) data [2]. As a consequence, the ageing rate, which is the rate between people who are more than 65 years old and those who are less than 20 , is far more superior in comparison to regional and national average ones. Indeed, this ratio rises to 113.2 in Lozère whereas it is "only" 92 in Occitanie and 76.4 at national level. Therefore, the population ageing is inevitable.

Because of this phenomenon, an increase of chronical diseases prevalence requiring polypharmacy has been noticed. This has consequences on the increase of drugs undesirable effects which is the root cause of 5 to $10 \%$ of 65 years old people hospitalisation and more than $20 \%$ for people who are more than 80 years old according to national study on undesirables effects linked to medical care (Eneis) [3]. Recent projections of this study have shown that the admission days of people aged above 75 years old will raise from $15 \%$ to $30 \%$. Thus polypharmacy has important direct impacts on patients [4]. We will focus here on medicated iatrogenesis.

L'âge, un facteur de risque à l'apparition des effets indésirables médicamenteux

According to the Eneis study [3], the medicine causes $20 \%$ of serious adverse events causes (AEC) which results in about 130,000 hospitalisations every year. In addition this study shows that almost half of AEC linked to drugs could be prevented which would lead to a reduction of hospitalisations, average admission days duration, beds occupancies, human resources needs and as consequence a decrease of health expenditure in the end. In this way, we should beforehand identify the patients, their situations and risk drugs. "Every noticed symptom on an elderly person must be considered as a drug side effect until proven otherwise".[5]

Finally, polypharmacy as well as the age increase the risk of adverse drugs effects (ADE) whose frequency rises exponentially with the number of prescribed medicines [6] [Table 1] in appendix. Therefore a side effect happens among $4 \%$ of patients taking 5 drugs a day, $10 \%$ for people taking 6 to 10 drugs a day, $28 \%$ for these who take 11 to 15 drugs a day and $54 \%$ for those taking more than 16 drugs a day [7-8].

\section{Pharmacokinetics on elderly patients}

Organism ageing has a direct impact on medicine pharmacokinetics. Indeed we observe a physiological evolution of patient which will have repercussions on drugs duration in the organism during the four steps of the medicine life cycle: absorption, distribution, metabolisation and elimination [Table 2] in appendix.

Furthermore, we know that with ageing, an alteration of the neurochemical transmission appears as well as a reduction of cognitive abilities and aptitudes [9]. It can be potentiated among mentally disturbed patients (cognitive troubles, mental agitations, ....). Nevertheless we found very few studies on iatrogenesis concerning elderly people who suffer from psychiatric troubles. Consequently, the medical centre François Tosquelles (Hospital Saint Alban, 48), which is a specialised institution in mental illness, has worked on medicine care among aging population in psychiatry and has elaborated an evaluation of professional practice on geriatric psychiatry polypharmacy.

\section{The notion of inappropriate medicine on elderly people}

It turned out some medicines used on elderly people have a benefit/ risk ratio too low to be considered as essential for these patients, even if they have a marketing authorisation (AMM). Therefore this observation has led to the concept of "inappropriate medicine". It is important to insist on the fact that those drugs are not prohibited and that the doctors have the right to prescribe them. Even if figures can be different according to the studies, they all agree on the fact that too many prescriptions are inappropriate for old people. Indeed it goes from $15 \%$ in the 2003 Onder \& Landi study which has been done on 800 people [10-11], to almost $45 \%$ in the 2005 Hajjar \& Hanlon study done on 384 hospitalised patients in 11 different hospital facilities. Besides, in Europe, almost $20 \%$ of elderly people take at least one inappropriate medicine. There are several references in this field but the most recognised ones are Beers criteria [12], the START-STOPP

Correspondence to: A Hamzaoui , Pharmacy Department and Medical Information Department , Francois Tosquelles Hospital, France, Tel: 078248 29 59; Email: Karim.hamzaoui@chft.fr

Key words: Polypharmacy, elderly patients, geriatric psychiatry, iatrogenesis, polypathology, drugstore, inappropriate medicines.

Received: November 03, 2017; Accepted: November 28, 2017; Published: December 02, 2017 
Table 1. Symptoms observed due to medicines.

\begin{tabular}{|l|l|}
\hline Neurological : & Cardiologic \\
- Extra pyramidal syndrome (neuroleptic) & - HypoTA (psychotropic drugs, antiHTA, \\
- Delirium symptom (BZD, anticholinergic) & - Rythm trouble (digoxine, hypokalemia ...) \\
- Falls (psychotropic drugs, antiHTA,) & - Bradycardia (betablocker, ...) \\
\hline Gastric & Urinary \\
- Neuroleptic constipation & - urinary retention (anticholinergic) \\
- Ulcer (AINS) & \\
\hline
\end{tabular}

Table 2. Pharmachokinetics modifications (ADME) due to the age

\begin{tabular}{|c|c|}
\hline ADME Phase & $\begin{array}{l}\text { Pharmachokinetics modification aged } \\
\text { patient / young patient }\end{array}$ \\
\hline Absorption & $\begin{array}{l}\text { - Decrease of stomach gastrointestinal } \\
\text { motility } \\
\text { - Blood flow decrease }\end{array}$ \\
\hline Distribution and transport & $\begin{array}{l}\text { - Decrease of water compartment } \\
\text { - Increase of fat mass } \\
\text { - Decrease of muscle mass } \\
\text { - decrease of albumin }\end{array}$ \\
\hline Metabolism & $\begin{array}{l}\text { Decrease of medicines hepatic } \\
\text { metabolism } \\
\text { - Decrease of hepatic blood flow }\end{array}$ \\
\hline Renal excretion & $\begin{array}{l}\text { - Decrease of renal blood flow } \\
\text { - Decrease of glomerular filtration }\end{array}$ \\
\hline
\end{tabular}

study [13-14] and the Laroche ML french criteria which all provide a list of inappropriate drugs for old people. Indeed the risk of adverse effects is twice higher among elderly people than for the young people [15].

The François Tosquelles hospital center (CHFT) has a 32 full time beds service for geriatric psychiatry. After several exchanges on the decrease of benzodiazepine prescriptions as well as on the analysis of medicine iatrogenesis cases on elderly people of the service, an improvement approach on taking medication has been initiated in 2009 with the doctor in charge of the service. After a two-years collaboration and with the help of all the medical team, a significant decrease of average length of stay (LOS) has been noticed: going from 72 days in 2009 to 54 days in 2011 which corresponds to a $25 \%$ drop. Moreover the average length of hospitalisation (LOH) has decreased as well of $22 \%$ going from 90 days in 2009 to 70 days in 2011 . Therefore, the beds occupation turnover has been improved and the service has been able to better fulfil external partners demands and as well as direction ones.

\section{Material and methods}

In 2011, it has been decided to go further and to study with precised figures the prescriptions pertinence with targeted audits in the service. This study consisted in retrospectively analyse the prescription of patient who have consulted a doctor or who have been hospitalized in our service. The goal was to make a situational analysis prescriptions given to polypathological patients who are more than 65 years old and who have been hospitalized. The project expected objectives are multiple either for patients (reduce iatrogenesis, the LOS and LOH), for the medical team (decrease the number of workplace accidents), the institution (bed occupation rationalization, active file increase, development of the prescription collegiality with the pharmacist) and for the collectivity with patient care safety and the savings related. We elaborated an audit grid inspired by the French professional college of geriatricians and the Laroche list [16]. In addition we took into account some programs of fight against medicine iatrogenesis from the French National Authority for Health (FNAH) and the National Agency for Medicines (ANSM) [17-19]. We also used the grid questions of the French professional college of geriatricians [20] to which we added questions on the variation of the prescribed drugs number between the entrance and the release of the patient. One question on benzodiazepine prescription rules given to an old person and one question about the presence of potentially inappropriate medicine (PIM) have also been added. Firstly a retrospective study has been realized on exit prescriptions of hospitalized patients in the gerontopsychiatry department and all other services (out of gerontpyschiatry) of the CHFT. Before realizing this audit, we have defined inclusion criteria which are: over 65 years old patients, polypathology and full time hospitalization. In order to do this, we have taken the computerized patient file (Cortexte) and the requests of data extracted from BusinessObjects which have been elaborated by the medical information department (MID). After the analysis of the first audit results, we have presented our conclusions to the institution in establishment medical commission (EMC) and during our hospital medicine committee meetings. Progressively we saw that people got quite interested in the subject so we decided to sensitize all the doctors through communications in EMC. Moreover, we have organized some trainings with external partners on elderly people medicine prescription. In addition we have checked if our first actions have brought results by auditing all CHFT services in 2016, but only on patients who have been present at the time of the audit in order to save time and energy. As a consequence the MID has been asked to send a request with the software BusinessObjects with the following criteria: over 65 years old and full time hospitalized the day of the audit cf (Table 3) in appendix

\section{Results}

With our different audits we have obtained the following results:

In the gerontopsychiatry department, the average age was 80.7 years old in 2011 and 79.2 years old in 2016. The patients entered with 8.8 medicines in 2011 and 11 in 2016 . They got out with 8.7 medicines per prescription including 3.7 psychotropic drugs, 2 benzodiazepines and 1.3 PIM whereas in 2016 the figures were 8.3 medicines per release prescription including 3.2 psychotropic drugs, 1.1 benzodiazepine and 0.9 PIM (Tables 4-7) in appendix.

In the services which are not specialized in the elderly people care, the average age was 81.8 years old in 2011 and 66.5 in 2016. The patients entered with 8.7 medicines in 2011 and 9 in 2016. They got out with 10.5 medicines per prescription including 3.6 psychotropic drugs, 1.6 benzodiazepine and 1.2 PIM whereas in 2016 the figures were 9 medicines per release prescription including 4.5 psychotropic drugs, 2.3 benzodiazepine and 2.3 PIM (Figures 1-3).

In the gerontopsychiatry department: In2011, 55.8\% of the patients had less than 2 prescribed benzodiazepines whereas this figure was $19.2 \%$ in 2016 . $43.2 \%$ had 2 prescribed benzodiazepines in 2011 versus 50\% in 2016 and $1 \%$ had 3 prescribed benzodiazepines in 2011 compared with $30.8 \%$ in 2016.

Benzodiazepines prescriptions in Saint Alban Hospital Center out of getonpsychiatry department: in 2011,36.4\% of the patients had less than 2 prescribed benzodiazepines whereas this figure was $25 \%$ in 2016. $36.4 \%$ had 2 prescribed benzodiazepines in 2011 versus $25 \%$ in 2016

Table 3. Activity collection in the gerontopsychiatry service between 2009 and 2011.

\begin{tabular}{|c|c|c|c|}
\hline DIM data & 2009 & 2010 & 2011 \\
\hline Active file & 113 & 116 & 137 \\
\hline Days & 10178 & 10408 & 9635 \\
\hline Hospital stays & 141 & 146 & 176 \\
\hline $\begin{array}{c}\text { LOS(days) vs CHFT } \\
\text { average }\end{array}$ & 72 vs 37,2 & 71 vs 35,8 & 54 vs 37 \\
\hline LOH (days) & 90 & 89 & 70 \\
\hline
\end{tabular}


Table 4. Patients analysis in the gerontopsychiatry service in 2011.

\begin{tabular}{|c|c|c|c|c|c|c|c|}
\hline $\begin{array}{c}\text { Gerontopsychiatry } \\
2011\end{array}$ & Sex distribution \% & Average ages & $\begin{array}{c}\text { Entrance medicines } \\
\text { number }\end{array}$ & $\begin{array}{l}\text { Exit medicines } \\
\text { number }\end{array}$ & Psychotropic drugs & benzodiazepine & $\begin{array}{l}\text { PIM among over } 65 \\
\text { years old people }\end{array}$ \\
\hline Women & $55,77 \%$ & 80,33 & 8,63 & 8,67 & 3,72 & 2,04 & 1,28 \\
\hline Men & $44,23 \%$ & 80,98 & 9,06 & 8,63 & 3,66 & 2,00 & 1,35 \\
\hline Total & $100 \%$ & 80,65 & 8,77 & 8,65 & 3,69 & 2,02 & 1,31 \\
\hline
\end{tabular}

Table 5. Patients analysis in the gerontopsychiatry service in 2016 .

\begin{tabular}{|c|c|c|c|c|c|c|c|}
\hline $\begin{array}{c}\text { Gerontopsychiatry } \\
2016\end{array}$ & Sex distribution \% & Average ages & $\begin{array}{c}\text { Entrance medicines } \\
\text { number }\end{array}$ & $\begin{array}{l}\text { Exit medicines } \\
\text { number }\end{array}$ & Psychotropic drugs & benzodiazepine & $\begin{array}{c}\text { PIM among over } 65 \\
\text { years old people }\end{array}$ \\
\hline Women & $69,2 \%$ & 79,1 & 11,94 & 7,72 & 3,28 & 1,11 & 1,06 \\
\hline Men & $31,8 \%$ & 79,8 & 8,38 & 9,63 & 3,0 & 1,13 & 0,75 \\
\hline Total & $100 \%$ & 79,2 & 11,0 & 8,3 & 3,2 & 1,1 & 0,9 \\
\hline
\end{tabular}

Table 6. Analysis of over 65 years old patients not treated in the dedicated service in 2011.

\begin{tabular}{|c|c|c|c|c|c|c|c|}
\hline $\begin{array}{c}\text { out of } \\
\text { gerontopsychiatry } \\
2011\end{array}$ & Sex distribution \% & Average ages & $\begin{array}{c}\text { Entrance medicines } \\
\text { number }\end{array}$ & $\begin{array}{l}\text { Exit medicines } \\
\text { number }\end{array}$ & Psychotropic drugs & benzodiazepine & $\begin{array}{l}\text { PIM among over } 65 \\
\text { years old people }\end{array}$ \\
\hline Women & $63,6 \%$ & 83 & 9,3 & 11,4 & 4,4 & 2 & 1 \\
\hline Men & 36,6 & 79,8 & 7,8 & 8,8 & 2,3 & 1 & 1,5 \\
\hline Total & 11 & 81,8 & 8,7 & 10,5 & 3,6 & 1,6 & 1,2 \\
\hline
\end{tabular}

Table 7. Analysis of over 65 years old patients not treated in the dedicated service in 2016.

\begin{tabular}{|c|c|c|c|c|c|c|c|}
\hline $\begin{array}{c}\text { out of } \\
\text { gerontopsychiatry } \\
2016\end{array}$ & Sex distribution \% & Average ages & $\begin{array}{c}\text { Entrance medicines } \\
\text { number }\end{array}$ & $\begin{array}{l}\text { Exit medicines } \\
\text { number }\end{array}$ & Psychotropic drugs & benzodiazepine & $\begin{array}{l}\text { PIM among over } 65 \\
\text { years old people }\end{array}$ \\
\hline Women & $50 \%$ & 67,5 & 10,5 & 9 & 3,5 & 2 & 1,5 \\
\hline Men & $50 \%$ & 65,5 & 7,5 & 11,5 & 5,5 & 2,5 & 3 \\
\hline Total & $100 \%$ & 66,5 & 9 & 10,3 & 4,5 & 2,3 & 2,3 \\
\hline
\end{tabular}

\section{Evolution of medicines number per prescription between entrance and exit in the gerontopsychiatry} service

diminution du nombre de ligne

nombre de ligne inchangé

augmentatioon nombre de ligne

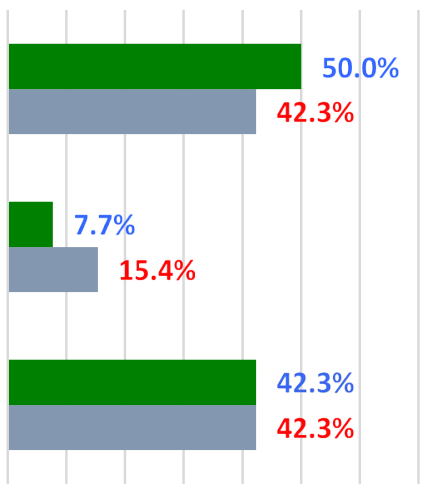

$0 \% 10 \% 20 \% 30 \% 40 \% 50 \% 60 \% 70 \% 80 \%$
- 2016

2011

Figure 1. Evolution of medicines number between entrance and exit in the gerontopsychiatry service between 2011 and 2016

and $27.2 \%$ had 3 prescribed benzodiazepines in 2011 compared with $50 \%$ in 2016 (Figure 4).

In the gerontopsychiatry service: $47.1 \%$ of patients had 1 PIM in 2011 whereas this figure was $38.5 \%$ in $2016.7 .7 \%$ had PIM in 2011 versus $3.8 \%$ in 2016 and $2.9 \%$ had 4 PIM in 2011 compared to $0 \%$ in 2016. The most prescribed PIM by decreasing order in 2011 were Zopiclone (47.1\%) Cyamémazine (21.2\%), Méprobamate (16.3\%), Lormétazépam, (8.7\%). In 2016 the ranking was Zopiclone (30.8\%), Alimémazine (11.5\%), Diazépam (11.5\%), Cyamémazine (7.7\%).

\section{Discussion}

Analysis of the patients age evolution. In the gerontopsychiatry service, between 2011 and 2016, we have seen no significant difference concerning the hospitalized patients aged during this period (2011: 80.6 years old, 2016: 79.2 years old). Nevertheless we can observe a decrease of the average patients age in the other services due to transfers of post emergency old patients to gerontopsychiatry service thanks to available beds increase because of the decrease of the LOS. 


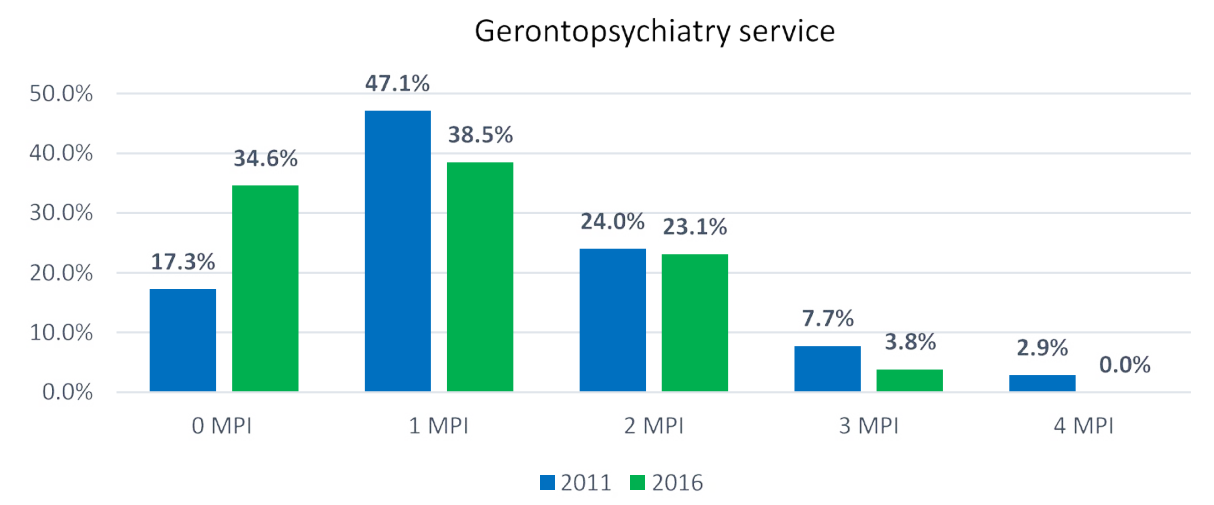

out of Gerontopsychiatry service

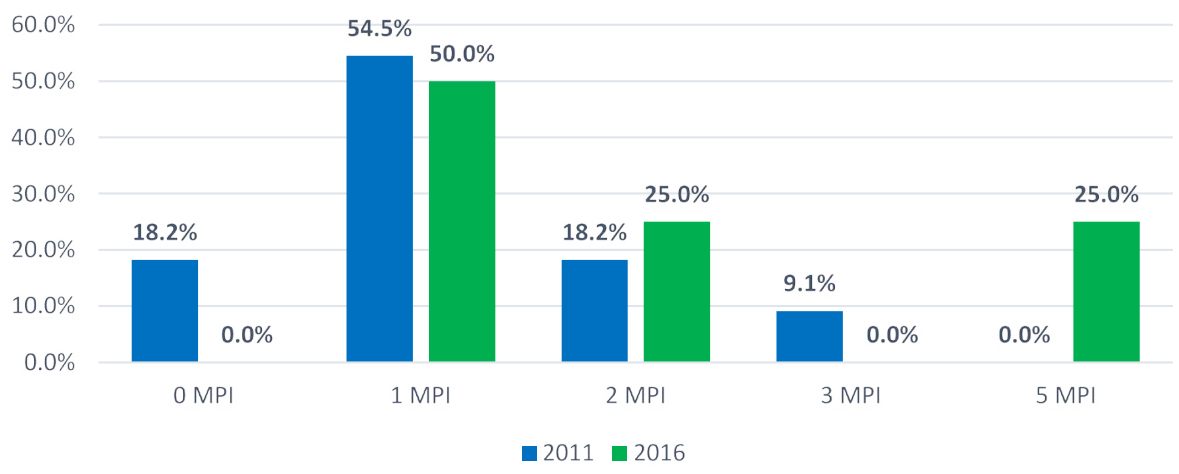

Figure 2. Prescription of potentially inappropriate medicines between 2011 and 2016.

Evolution du nombre de médicament par ordonnance entre l'entrée et la sortie hors gerontopsychiatrie

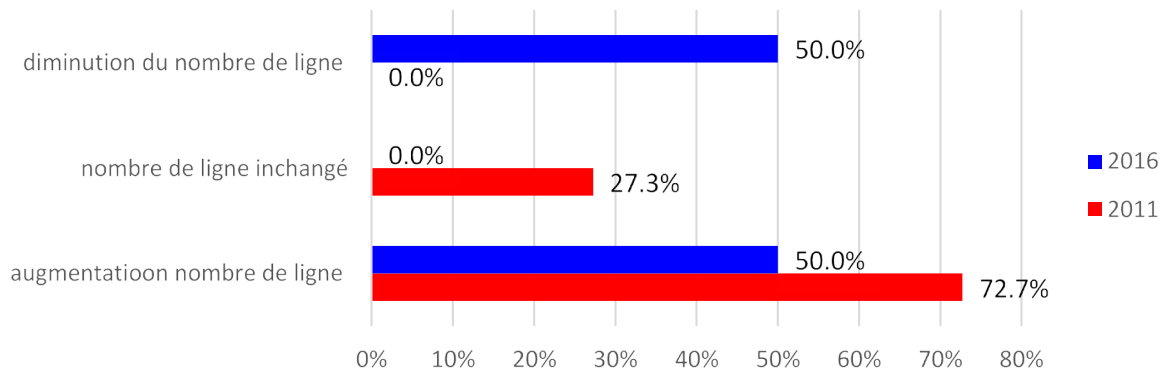

Figure 3. Evolution of medicines number between entrance and exit out of the gerontopsychiatry service between 2011 and 2016.

Number of medicines per subscription. We notice that patients arrive in the service with a lot of drugs ( 8.8 in 2011, 8.3 in 2016). So we observe in 2016 that prescriptions are less loaded between the entrance and the release which lead to the conclusion to a certain extent that our approach has been efficient. Thus, prescriptions contain less psychotropic drugs, benzodiazepines and inappropriate medicines. The beds occupation turnover increase allowed us to take care of patients with heavier treatments so with more drugs.

Prescription of psychotropic drugs. The average prescription of psychotropic drugs was 3.69 in 2011 and 3.02 in 2016. The real evolution is noticed on the number of prescriptions containing 6 or more psychotropic drugs. There were $26.9 \%$ in 2011 whereas the figure was $7.6 \%$ in 2016.
An adjustment has been realised on the most polymedicated patients whose prescriptions contained psychotropic drugs, even if doctors still give between 4 and 6 psychotropic drugs per prescription. Most of patients get between 4 and 5 psychotropic drugs $(53.8 \%$ in $2011,65.4 \%$ in 2016).

Prescription of benzodiazepine. In the gerontopsychiatry service :

We have noticed an important increase of benzodiazepines between 2011 and 2016. This can be explained by the psychotropic and inappropriate drugs prescription decrease. In other services, in 2011, $36.4 \%$ of patients took less than 2 benzodiazepines, $36.4 \%$ took 2 of them and $27.2 \%$ took less than of those medicines. On the contrary, in 2016, we observe an over-prescription of benzodiazepines: $50 \%$ of patients took 3 benzodiazepines which almost the double. 

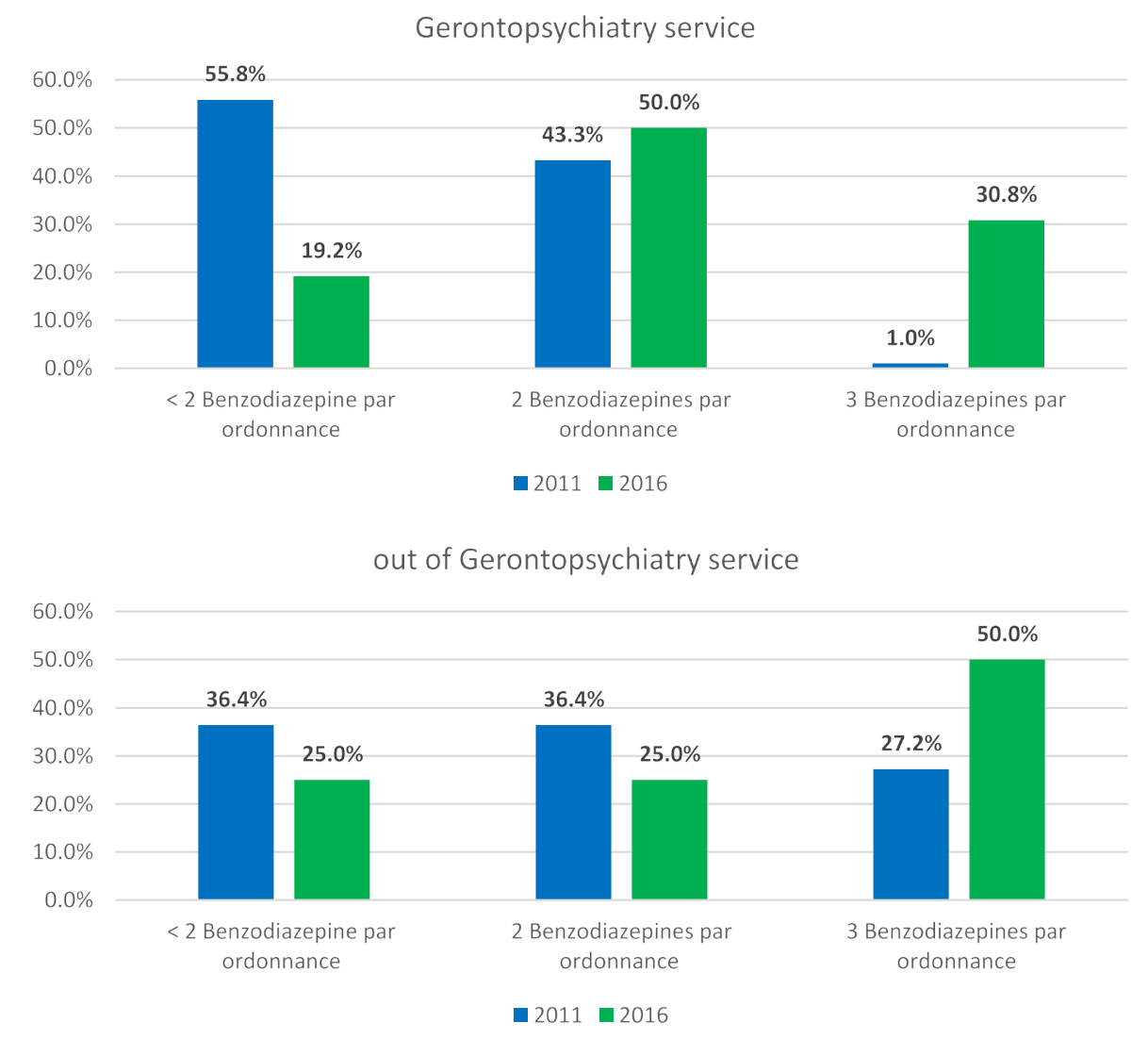

Figure 4. Prescription of benzodiazepines between2011 et 2016.

Potentially inappropriate medicines. The inappropriate medicines study on hospitalised patients in the gerontopsychiatry service highlights a significant evolution between 2011 and 2016. Indeed in 2011, 47\% of patients consumed Zopiclone whereas in 2016 they were $0 \%$. Moreover, the Cyamemazine consumption has been divided by 3 going from $21 \%$ to $7 \%$. Nevertheless, the figures evolved the other way in other services. For example, the Zopiclone consumption has doubled in 2016 reaching the $75 \%$. In addition, we notice in 2016 that the prescription and the use of inappropriate have surged going from 1.2 to 2.3 in 2016 . The increase is due to new doctors arrival who are not alerted to PIM

Results synthesis. They can be justified by more factors, particularly the lack of geriatricians and geriatric psychiatrist in other services. Additionnally, there has been a huge medical turnover between the 2 audits and doctors who arrived in 2016 did not get the awareness on elderly people prescription. Besides we can highlight the fact that in those services the entering people are in crisis. In these cases the priority is to treat the psychic crisis with the medicine which gives an immediate effect.

\section{Conclusion}

Elderly people need more attention from health care professionals. Indeed these people are naturally fragile due to organism evolution. As a consequence they can be more easily subject to polypharmacy treatments due to several diseases. Furthermore, due to the age other causes can lead to iatrogenesis: drugs pharmacodynamics and pharmacokinetics. In addition, even if we except the age factor, there are individual variations: people who are the same age can react differently according to the receptors number or the medicine effect variation from the receptor. Consequently some organs are particularly sensitive to the following drugs:

> Brain psychotropic drugs

> Bladder anticholinergic (high retention)

> Autonomous nervous system with conter-regulation mechanisms becoming less efficient (orthostatic hypotension, urinary incontinence, ...)

However, even if we collected data on elderly people medicines, we have to underline that clinical tests still are insufficient: only $5 \%$ of drugs have been evaluate whereas they represent $40 \%$ of the consumption. This paradoxe can be explained by the fact that there are only a few reference medicines which have been studied on old people (be it in good health of polypathological). Clinical studies on medicines are based on data obtained on voluntary people and are divided in 3 steps which need targeted patients" with different profiles: sound volunteers, volunteer patients who have the targeted illness. Concerning Phase I, there is an inclusion issue because we call volunteer subjects but an ethical problem appears too: shall we or can we take the risk to see unexpected adverse effects appear on vulnerable people [21-22]? It is only after the AMM that pharmacovigilance center can collect and analyse at big scale and in real conditions the drugs effects on polypathological elderly people. The evolution of the described project could be a similar study for half time hospitalized patients and those who get ambulatory treatment. 


\section{References}

1. http://www.scansante.fr/

2. www.insee.fr

3. Salesses, Perez, Maillard, Blanchard, Mallard (2016) Effect of dosimeter's position on occupational radiation extremity dose measurement for nuclear medicine workers during (18)F-FDG preparation for PET/CT. EJNMMI Phys 3: 16. [Crossref]

4. Ferchichi, Antoine V (2004) Appropriate drug prescribing in the elderly. Rev Med Interne 25: 582-590. [Crossref]

5. Gurwitz et coll (1995) Long-term Care Quality Letter - Brown University

6. The annals of pharmacotherapy 2015

7. Karas S. Ann Emerg Med, (1981) Sloan RW - Am Fam Physician, 1983.

8. Gurwitz JH, Field TS, Avorn J, McCormick D, Jain S (2000) Incidence and preventability of adverse drug events in nursing homes. Am J Med. 109: 87-94 [Crossref]

9. Mangoni AA, JacksonSH (2004) Age-Related Changes in Pharmacokinetics:Basic Principals \& Practical Applications. Br J Clin Pharmacol [Crossref]

10. Onder G, Landi F, Cesari M, Gambassi G, Carbonin et al., (2003) Investigators of the GIFA Study. Inappropriate medication use among hospitalized older adults in Italy: results from the Italian Group of Pharmacoepidemiology in the Elderly. Eur J Clin Pharmacol 59: 157-62 [Crossref]

11. Hajjar ER1, Hanlon JT, Sloane RJ, Lindblad CI, Pieper CF (2005) Unnecessary drug use in frail older people at hospital discharge. J Am Geriatr Soc 53: 1518-1523. [Crossref]

12. Gray SL1, Anderson ML2, Dublin S3, Hanlon JT4, Hubbard R5 (2015) Cumulative use of strong anticholinergics and incident dementia: a prospective cohort study. JAMA Intern Med 175: 401-407. [Crossref]
13. Beers MH (1997) Explicit criteria for determining potentially inappropriate medication use by the elderly. An update. Arch Intern Med. 157: 1531-1536. [Crossref]

14. Gallagher P, Ryan C, Byrne S, Kennedy J, O’Mahony D (2008) STOPP (Screening Tool of Older Person's Prescriptions) and START (Screening Tool to Alert doctors to Right Treatment). Consensus validation. Int J Clin Pharmacol Ther 46: 72-83. [Crossref]

15. Laroche ML, Charmes JP, Merle L (2007) Potentially inappropriate medications in the elderly: a French consensus panel list. Eur J Clin Pharmacol 63: 725-31 [Crossref]

16. cBr J Clin Pharmacol (2002).

17. Laroche ML. (2009) Médicaments potentiellement inappropriés aux personnes âgées intérêt d'une liste adaptée à la pratique médicale française. Rev Med Interne 30: 592601. [Crossref]

18. Guide de bon usage de (2005) l'AFSSAPS Prévenir la iatrogénèse médicamenteuse chez le sujet âgé, AFSSAPS

19. Programme PMSA de la HAS Prescription médicamenteuse chez le sujet âgé, Programmes Pilotes, HAS.

20. Choix des benzodiazépine mémobenzo, HAS

21. grille CPGF (Collège Professionnel des Gériatres Français)

22. ART L 11211 du code de la santé publique et

23. Loi $\mathrm{N}^{\circ} 2004-806 \mathrm{du} 09$ aout 2004 relative à la politique de sante publique

24. directive européenne n²001/20/CE du 04 avril 2001 la loi Huriet

Copyright: $@ 2017$ Hamzaoui A. This is an open-access article distributed under the terms of the Creative Commons Attribution License, which permits unrestricted use, distribution, and reproduction in any medium, provided the original author and source are credited. 